\title{
BMJ Open Hepatitis B virus infection in Chinese patients with hepatitis $C$ virus infection: prevalence, clinical characteristics, viral interactions and host genotypes: a nationwide cross-sectional study
}

\author{
Li-Bo Yan, ${ }^{1,2}$ Hui-Ying Rao, ${ }^{3}$ Yuan-Ji Ma, ${ }^{1,2}$ Lang Bai, ${ }^{1,2}$ En-Qiang Chen, ${ }^{1,2}$ \\ Ling-Yao Du, ${ }^{1,2}$ Rui-Feng Yang, ${ }^{3}$ Lai Wei, ${ }^{3}$ Hong Tang, ${ }^{1,2}$ CCgenos Study Group
}

To cite: Yan L-B, Rao H-Y, Ma Y-J, et al. Hepatitis B virus infection in Chinese patients with hepatitis $\mathrm{C}$ virus infection: prevalence, clinical characteristics, viral interactions and host genotypes: a nationwide cross-sectional study. BMJ Open 2016;6:e012016. doi:10.1136/bmjopen-2016012016

- Prepublication history for this paper is available online. To view these files please visit the journal online (http://dx.doi.org/10.1136/ bmjopen-2016-012016).

Received 23 March 2016 Revised 7 September 2016 Accepted 8 September 2016

CrossMark

For numbered affiliations see end of article.

\section{Correspondence to}

Professor Hong Tang; htang6198@hotmail.com and Professor Lai Wei; weilai@ pkuph.edu.cn

\section{ABSTRACT}

Objectives: Little is known about hepatitis $B$ virus (HBV) infection in patients with hepatitis $C$ virus (HCV) infection in China. This study aimed to evaluate the prevalence, clinical characteristics, viral interactions and host genotypes of HBV/HCV dual infection compared with HCV monoinfection.

Study design: A cross-sectional study.

Setting: China.

Participants and methods: 997 patients with HCV from 28 university-affiliated hospitals in China were enrolled in this research. Patients were divided into two subgroups.

Results: The prevalence of HBV infection in patients with HCV was $4.11 \%$ (41/997). The age-specific prevalence of $\mathrm{HBsAg}$ was $0.70 \%, 3.97 \%$ and $5.85 \%$ in groups aged $18-30,30-50$ and $>50$ years old $(p=0.057)$, respectively. Patients with HBV/HCV dual infection and patients with HCV monoinfection had similar HCV viral loads $(5.80 \pm 0.89$ vs $5.83 \pm 1.00$ $\log 10 \mathrm{lU} / \mathrm{mL}, \mathrm{p}=0.904)$. The dominant HCV genotype was $1 b$ in both groups ( $53.65 \%$ vs $56.90 \%, p=0.493$ ). The protective $\mathrm{C}$ allele in IL-28B ( $\mathrm{rs} 12979860)$ was also the dominant allele type in both patient groups $(85.36 \%$ vs $83.99 \%, p=0.814)$. Patients with HBV/HCV dual infection had a higher ratio of liver cirrhosis and hepatic decompensation than patients with HCV monoinfection $(39.02 \%$ vs $17.69 \%$, $p=0.001 ; 31.70 \%$ vs $12.13 \%, p=0.001)$.

Conclusions: The HBV burden was moderate in HCVinfected patients in China. Liver cirrhosis was more common in patients with HBV/HCV dual infection, suggesting the need for closer monitoring of dualinfected individuals.

Trial registration number: NCT01293279;

Post-results.

\section{INTRODUCTION}

Hepatitis B virus (HBV) and hepatitis $\mathrm{C}$ virus (HCV) infections are the most common

\section{Strengths and limitations of this study}

- This was a nationwide, multicentre, crosssectional study.

- The sample size was sufficient to detect the prevalence of hepatitis B virus (HBV) dual infection in patients with hepatitis $\mathrm{C}$ virus (HCV).

- This study detected the host genotypes of IL28B in both $\mathrm{HBV} / \mathrm{HCV}$ dual infection and $\mathrm{HCV}$ monoinfection.

- The data in this study did not provide HBV DNA levels and $\mathrm{HBeAg} / \mathrm{anti}-\mathrm{HBe}$ status due to the shortage of serum in the dual-infection group.

- There were no available data on occult HBV since HBV DNA was not performed. This might underestimate the real burden of HBV in this study population.

- No sequencing of HBV genes was performed, which could have provided insights into molecular epidemiology, escape mutations and drugresistance variants in this study population.

- There was no quantitative measurement of HBsAg, which could have provided insights into the metabolic effect of covalently closed circular DNA in the liver.

causes of chronic liver disease, cirrhosis and hepatocellular carcinoma, affecting approximately 350 million and 170 million people worldwide, respectively. ${ }^{1-5}$ In China, HBV and HCV affect about 93 million and 10-30 million people, respectively. Dual infection with HBV and HCV is not uncommon because the two viruses share similar paths of transmission, especially in areas where they are endemic. ${ }^{2}$

The worldwide prevalence of $\mathrm{HBV} / \mathrm{HCV}$ dual infection varies in different regions because of the different geographical distribution of the two viruses. Studies from the USA, Taiwan, Japan, India, Italy and China 
have found an estimated prevalence of $\mathrm{HBV} / \mathrm{HCV}$ dual infection of approximately 3.4-23\% in hepatitis B surface antigen (HBsAg)-positive patients. ${ }^{6-8}$ The prevalence of HBV infection among patients with HCV in the USA was estimated to be $1.3-5.8 \%{ }^{6-8}$ However, most information on $\mathrm{HBV} / \mathrm{HCV}$ dual infection has come from studies on populations with chronic $\mathrm{HBV}$ infection, especially in China. Very little is known about the prevalence of HBV/ $\mathrm{HCV}$ dual infection among patients with HCV in China because of the lack of multicentre large-scale studies. ${ }^{9}$

$\mathrm{HBV} / \mathrm{HCV}$ dual infection is of great interest, with studies showing interactions between these two viruses. A critical question that has not been answered is whether HBV and HCV interfere with each other's life cycles during $\mathrm{HBV} / \mathrm{HCV}$ dual infection. Some studies have shown that HBV may inhibit HCV RNA replication, ${ }^{10}$ while others have proved the total opposite, with HCV RNA levels being the same in both patients with $\mathrm{HBV} / \mathrm{HCV}$ dual infection and those with only HCV infection. ${ }^{7}$ With such controversial discoveries, it appeared important to better understand viral interactions in $\mathrm{HBV} / \mathrm{HCV}$ dual infection.

The clinical characteristics of patients with $\mathrm{HBV} / \mathrm{HCV}$ dual infection are important in designing treatment strategies. Moreover, many aspects of dual infection remain largely unknown, including biochemical and virological characteristics and host genotypes. ${ }^{11}$ These variables may be associated with disease severity and are thus important in therapeutic management.

There are even fewer data available for patients with $\mathrm{HBV} / \mathrm{HCV}$ dual infection in China. In this study, we evaluated dual HBV/HCV infection in Chinese patients with HCV by analysing epidemiological, biochemical and virological characteristics, host genotypes and the prevalence of cirrhosis.

\section{METHODS}

\section{Materials and study design}

From February to June 2011, 1012 HCV-positive patients were enrolled from the outpatient facilities of 28 university-affiliated hospitals across China. All patients in this study had to meet the following two criteria: 18 years or older and HCV infection confirmed or reconfirmed (antibody to HCV and HCV RNA positive) in the 90 days before enrolment. Patients who had received antiviral or interferon-based treatment for hepatitis C or hepatitis B were excluded.

Of the 1012 participants, two were excluded because of failure to obtain consent. HCV infection was not confirmed within 90 days before enrolment for nine patients. Four patients failed to have a physical examination and blood sampling within 9 days of providing informed consent. Eventually, 997 patients were included in the final research.

In this nationwide, multicentre, cross-sectional study, demographic information, medical histories, physical examinations and blood samples were obtained within
9 days of enrolment. All patients were interviewed to collect data on their lifestyle, HCV transmission risk factors, and other relevant variables. ${ }^{12}$ All patients were divided into two subgroups on the basis of their HBsAg status.

\section{Ethics statement}

All patients provided written informed consent before being enrolled. In addition, each patient was provided with relevant documentation and consent to study requirements. The study was approved by the institutional review board or ethics committee at each centre and complied with the provisions of the Good Clinical Practice guidelines for cross-sectional studies.

\section{Biological and virological variables}

Patients were examined in the hospital where they were enrolled for routine blood biochemistry and haematology tests. Their samples were collected and sent to Peking University Hepatology Institute (CapitalBio, Beijing, China) for further virological and genetic analyses. Blood samples were shipped under appropriate conditions to the central laboratory in Beijing where $\mathrm{HCV}$ viral genotype and HCV viral load were tested.

The HCV viral load was determined using Abbott RealTime HCV Genotype II (Abbott Laboratories, Des Plaines, Illinois, USA). Six different genotypes of HCV were assessed using the Versant HCV Genotype 2.0 Assay (LiPA) from Siemens according to the manufacturer's instructions (Siemens Healthcare Diagnostics, Tarrytown, New York, USA). HBsAg status was measured with a microparticle ELISA at Peking University People's Hospital (Abbott Laboratories, Abbott Park, Illinois, USA).

\section{Single-nucleotide polymorphisms (SNPs) genotyped in the IL28B genomic region}

Peripheral blood samples were collected from all participants following standard procedures and stored in tubes with EDTA. Genomic DNA was extracted from $200 \mu \mathrm{L}$ of sample using the cell suspension genomic DNA extraction kit (Qiagen, Milan, Italy) according to the manufacturer's instructions. All DNA extraction samples were stored at $-70^{\circ} \mathrm{C}$ until further use. Thirteen SNPs within the IL28B genomic region were genotyped. The host genotype was identified with iPLEX Gold (Sequenom, San Diego, California, USA) at CapitalBio, a platform that could map SNPs. For genetic markers, we applied the following quality control criteria: call rate $<90 \%$, Hardy-Weinberg p value $<0.005$ or low-quality genotype clustering. No individual was excluded because of a high genotyping call rate.

\section{Diagnosis of liver cirrhosis and fatty liver}

Cirrhosis was diagnosed by liver biopsy, or Fibroscan (Echosens, Paris, France) score of more than $13 \mathrm{kPa}$, or radiological image showing nodular liver or splenomegaly combined with platelet count below 100000 . Decompensated cirrhosis was defined as cirrhosis with sequelae such as ascites, variceal bleeding, hepatic 
encephalopathy or hepatorenal syndrome. ${ }^{12}$ Fatty liver was diagnosed using liver biopsy or hepatic imaging (hepatic ultrasound, CT, MRI). ${ }^{12}$

\section{Data quality control and validation}

Peking University People's Hospital and Bristol-Myers Squibb designed the protocol. All data were inputted into the electronic data capture system at each centre and were examined by one clinical research associate. The contract research organisation controlled and validated the data quality.

\section{Statistical analysis}

Data were analysed using SPSS software V.17.0 for Windows. Measurement data were presented as median and IQR (range minimum-maximum) and were examined using the Wilcoxon rank sum test. HCV RNA levels were log-transformed, presented as mean $\pm \mathrm{SD}$ and examined using the Student t test. Categorical variables were expressed as counts and proportions and examined using the $\chi^{2}$ test or Fisher's exact test. Logistic regression analysis was used to identify independent factors associated with $\mathrm{HBV} / \mathrm{HCV}$ dual infection. $\mathrm{p} \leq 0.05$ (twotailed) was considered to indicate significance.

\section{RESULTS}

\section{Prevalence of $\mathrm{HBV} / \mathrm{HCV}$ dual infection in patients} with HCV

Basic demographic and clinical characteristics of participants are shown in table 1 . The majority were male, with a median age of 46 years (range 18-77) and a mean HCV viral load of $5.83 \pm 1.00 \log 10 \mathrm{IU} / \mathrm{mL} ; 18.56 \%$ had cirrhosis. Of the $997 \mathrm{HCV}$-positive patients, $41(4.11 \%)$ were $\mathrm{HBsAg}$ positive (figure 1 ). HBsAg prevalence by age was $0.70 \%, 3.97 \%$ and $5.85 \%$ for age groups $18-30$, $30-50$ and $>50$ years old, respectively $(\mathrm{p}=0.057)$.

\section{Sociodemographic characteristics and risk factors for HBV/HCV dual infection}

The sociodemographic characteristics and risk factors for $\mathrm{HBV} / \mathrm{HCV}$ dual infection with or without HBsAg are listed in table 2. Subjects with HBV/HCV dual infection were more likely to be older than 30 years $(\mathrm{p}=0.042$, $\mathrm{OR}=0.162,95 \%$ CI 0.022 to 1.187 ). Gender, residence in the south of China, a history of blood transfusion and

\begin{tabular}{ll} 
Table 1 Clinical characteristics of patients & \\
\hline Characteristic & Value \\
\hline Male sex, n (\%) & $546(54.7)$ \\
Mean age, years (range) & $46(18-77)$ \\
HBsAg positive, n (\%) & $41(4.11)$ \\
Log10 hepatitis C virus RNA, IU/mL (range) & $5.83 \pm 1.00$ \\
Alanine transaminase, IU/L (range) & $55(6-1301)$ \\
Aspartate transaminase, IU/L (range) & $153(11-541)$ \\
Cirrhosis, n (\%) & $185(18.56)$ \\
\hline
\end{tabular}

host IL28B genotype were not associated with the presence of HBsAg $(\mathrm{p}=0.861, \mathrm{p}=0.089, \mathrm{p}=0.448, \mathrm{p}=0.815$, respectively).

\section{Clinical characteristics of patients with HBV/HCV} and patients with HCV alone

Patients were divided into two subgroups based on their HBsAg status: 41 patients with $\mathrm{HBV} / \mathrm{HCV}$ dual infection; 956 patients with HCV monoinfection. The clinical characteristics of the two subgroups of patients are listed in table 3. The main path of virus transmission was blood transfusion in both groups. In both groups, the major path of virus transmission for patients with genotype 1 or 2 was blood transfusion, while it was drug injection or other paths for patients with genotype 3 or 6 (24/32 vs $2 / 9, \mathrm{p}=0.006$; $526 / 811$ vs $23 / 145, \mathrm{p}<0.000)$. Biochemical characteristics, including alanine transaminase, aspartate transaminase, total bilirubin, albumin, glutamine transferase, total cholesterol and platelets, were all similar in the two groups.

\section{Virological characteristics of patients with $\mathrm{HBV} / \mathrm{HCV}$} and patients with HCV alone

Results of HCV RNA and HCV genotype analysis are listed in table 3. The level of serum HCV RNA was 5.80 $\pm 0.89 \log 10 \mathrm{IU} / \mathrm{mL}$ for the dual-infection group and $5.83 \pm 1.00 \log 10 \mathrm{IU} / \mathrm{mL}$ for the $\mathrm{HCV}$ monoinfection group $(\mathrm{p}=0.904)$.

The main HCV genotype for both groups was $1 \mathrm{~b}$, followed by genotypes 2, 3 and 6 . Genotypes 4 and 5 were not found. There was no difference in HCV genotypes between the two groups (23/41 vs 559/956, $\mathrm{p}=0.493)$. Twenty-one patients $(2.1 \%)$ were infected with multiple genotypes in the HCV monoinfection group.

\section{Host genotypes of IL28B in patients with HBV/HCV} and patients with HCV alone

In this study, $85.36 \%$ of patients with dual infection had IL28B genotype CC (rs12979860), while $83.99 \%$ of HCV

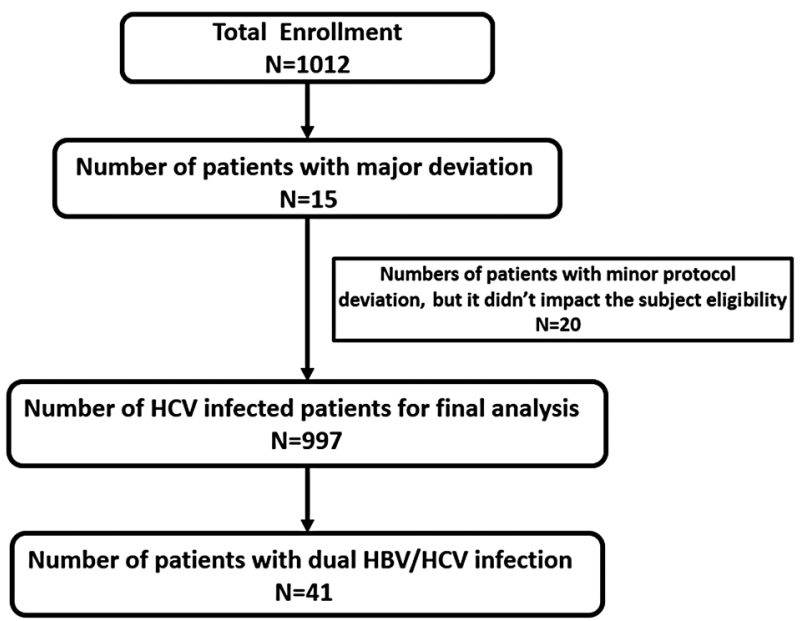

Figure 1 Flow chart of this cross-sectional observational study. 
Table 2 Sociodemographic characteristics, potential risk factors and host genotypes for HBsAg positivity in HCV-infected patients

\begin{tabular}{lllll}
\hline Characteristic & $\begin{array}{l}\text { HBsAg positive } \\
\text { (HBV+HCV) }(\mathbf{n = 4 1 )}\end{array}$ & $\begin{array}{l}\text { HBsAg negative } \\
\text { (HCV) }(\mathbf{n = 9 5 6 )}\end{array}$ & OR (95\% Cl) & p Value \\
\hline Sex male & $23(56.10)$ & $523(54.70)$ & $0.945(0.504$ to 1.775) & 0.861 \\
Age $\geq 30$ years & $40(97.56)$ & $828(86.61)$ & $0.162(0.022$ to 1.187$)$ & 0.042 \\
Residence in south China & $25(60.97)$ & $452(47.28)$ & $1.742(0.918$ to 3.305) & 0.089 \\
Blood transfusion & $26(63.41)$ & $549(57.42)$ & $1.285(0.672$ to 2.457$)$ & 0.448 \\
rs12979860CC & $35(85.36)$ & $803(83.99)$ & $1.111(0.452$ to 3.289) & 0.814 \\
\hline
\end{tabular}

Values are $n(\%)$.

HBsAg, hepatitis B surface antigen; HBV, hepatitis B virus; HCV, hepatitis C virus.

Table 3 Clinical and virological characteristics in HCV-infected patients according to HBsAg status

\begin{tabular}{|c|c|c|c|}
\hline Characteristic & $\begin{array}{l}\text { HBsAg positive } \\
(\mathrm{HBV}+\mathrm{HCV})(n=41)\end{array}$ & $\begin{array}{l}\text { HBsAg negative } \\
\text { (HCV) }(n=956)\end{array}$ & p Value \\
\hline Male sex, n (\%) & $23(56.10)$ & $523(54.70)$ & 0.861 \\
\hline Median age, years (range) & $51(28-68)$ & $45(18-77)$ & 0.909 \\
\hline \multicolumn{4}{|l|}{ Mode of transmission, $\mathrm{n}(\%)$} \\
\hline Transfusion & $26(63.41)$ & $549(57.43)$ & \multirow[t]{2}{*}{0.448} \\
\hline Intravenous drug use and other & $15(36.59)$ & 407 (42.57) & \\
\hline Alanine transaminase, IU/L (range) & $45(13-483)$ & $56(6-1301)$ & 0.064 \\
\hline Aspartate transaminase, IU/L (range) & $46(20-330)$ & $46(12-587)$ & 0.542 \\
\hline Total bilirubin, $\mu \mathrm{mol} / \mathrm{L}$ (range) & $15.1(5.3-412.9)$ & $15.0(3.1-280.8)$ & 0.841 \\
\hline Albumin, g/L (range) & $43.1(26.5-51.3)$ & $44.4(18.2-58.7)$ & 0.065 \\
\hline Glutamine transferase, IU/L (range) & $36(10-453)$ & $37(6-712)$ & 0.715 \\
\hline Total cholesterol, $\mathrm{mmol} / \mathrm{L}$ (range) & $4.08(1.89-5.45)$ & $4.00(1.01-12.51)$ & 0.779 \\
\hline Platelets, $10^{9} / \mathrm{L}$ (range) & $140(50-375)$ & $155(11-541)$ & 0.700 \\
\hline Log10 HCV RNA, IU/mL (mean $\pm S D)$ & $5.80 \pm 0.89$ & $5.83 \pm 1.00$ & 0.904 \\
\hline Genotypes, n (\%) & & & 0.493 \\
\hline 1 & $23(56.10)$ & $559(58.47)$ & \\
\hline $1 b$ & $22(53.65)$ & $544(56.90)$ & \\
\hline $1 \mathrm{a}$ & $1(2.44)$ & $13(1.36)$ & \\
\hline 2 & $9(21.95)$ & $231(24.16)$ & \\
\hline 3 & $4(9.75)$ & $87(9.10)$ & \\
\hline 6 & $5(9.75)$ & $58(6.06)$ & \\
\hline Multiple genotypes* & $0(0)$ & $21(2.19)$ & \\
\hline
\end{tabular}

monoinfected patients had IL28B genotype CG $(\mathrm{rs} 12979860) \quad(\mathrm{p}=0.814)$. The frequency distribution of IL28B host genotypes for the other 12 SNPs based on HBV infection is shown in table 4. No IL28B host genotypes showed evidence of strong statistical association with $\mathrm{HBV} / \mathrm{HCV}$ dual infection.

\section{Prevalence of liver cirrhosis and fatty liver in HBV/HCV} dual-infected patients

Cirrhosis was reported in $18.56 \%$ of all cases. Further analysis showed that 16 of the 41 patients with $\mathrm{HBV} /$ HCV $(39.02 \%)$ and 169 of the 956 patients with HCV $(17.68 \%)$ had cirrhosis, showing that cirrhosis was more common in patients with $\mathrm{HBV} / \mathrm{HCV}$ dual infection than in those with HCV monoinfection (16/41 vs 169/956, $\mathrm{p}=0.001$ ). Similarly, decompensated cirrhosis was more common in patients with $\mathrm{HBV} / \mathrm{HCV}$ dual infection than in those with HCV monoinfection (13/41 vs $116 / 956$, $\mathrm{p}=0.001)$. The prevalence of fatty liver was similar in the two groups (3/41 vs 92/956, $\mathrm{p}=0.621$ ) (figure 2 ).

\section{DISCUSSION}

The prevalence of coinfection with $\mathrm{HBV}$ and $\mathrm{HCV}$ is unknown because of the lack of large-scale studies in China. As HBV and HCV infection are highly endemic, it is essential to investigate the prevalence of $\mathrm{HBV} / \mathrm{HCV}$ dual infection in China. The epidemiological study performed by Chen et al ${ }^{13}$ showed that the anti-HCV positive rate was $14.47 \%$ in chronic hepatitis B (CHB) patients. Another study showed that the anti-HCV positive rate was $11.39 \%$ among patients infected with HBV in China. ${ }^{14}$ However, most information on the prevalence and predictors of $\mathrm{HBV} / \mathrm{HCV}$ coinfection has 
Table 4 Distribution of host IL28B genotypes in $\mathrm{CHC}$ patients according to HBsAg status

\begin{tabular}{|c|c|c|c|c|}
\hline Host genotype IL28B & Alleles & HBsAg positive $(\mathrm{HBV}+\mathrm{HCV})(\mathrm{n}=41)$ & HBsAg negative (HCV) $(n=956)$ & p Value \\
\hline \multirow[t]{2}{*}{ rs12979860 } & $\mathrm{CC}$ & $35(85.36)$ & 803 (83.99) & 0.814 \\
\hline & $\mathrm{CT} / \mathrm{TT}$ & $6(14.63)$ & $153(17.87)$ & \\
\hline \multirow[t]{2}{*}{ rs8099917 } & $\mathrm{TT}$ & 35 (85.36) & $813(85.04)$ & 0.955 \\
\hline & GT/GG & $6(14.63)$ & $143(15.95)$ & \\
\hline \multirow[t]{2}{*}{ rs11881222 } & AA & $35(85.36)$ & 796 (83.26) & 0.723 \\
\hline & GA/GG & $6(14.63)$ & 160 (16.73) & \\
\hline \multirow[t]{2}{*}{ rs10853728 } & CC & 32 (78.04) & 619 (64.75) & 0.080 \\
\hline & $\mathrm{CG} / \mathrm{GG}$ & 9 (21.95) & 337 (35.25) & \\
\hline \multirow[t]{2}{*}{ rs28146813 } & GG & $6(14.63)$ & $154(16.11)$ & 0.801 \\
\hline & GC & 35 (85.36) & $802(83.89)$ & \\
\hline \multirow[t]{2}{*}{ rs4803219 } & $\mathrm{CC}$ & 35 (85.36) & 805 (84.21) & 0.842 \\
\hline & CT & $6(14.63)$ & 151 (15.79) & \\
\hline \multirow[t]{2}{*}{ rs4803223 } & AA & 35 (85.36) & $802(83.89)$ & 0.801 \\
\hline & GA/GG & $6(14.63)$ & $154(16.11)$ & \\
\hline \multirow[t]{2}{*}{ rs7248668 } & GG & 35 (85.36) & 813 (85.04) & 0.955 \\
\hline & GA/AA & $6(14.63)$ & $143(14.96)$ & \\
\hline \multirow[t]{2}{*}{ rs12980275 } & AA & 34 (82.92) & 799 (83.58) & 0.912 \\
\hline & GA/GG & $7(17.07)$ & 157 (16.42) & \\
\hline \multirow[t]{2}{*}{ rs8103142 } & CT & 34 (82.92) & 758 (79.29) & 0.572 \\
\hline & $\mathrm{TC} / \mathrm{CC} / \mathrm{TT}$ & 7 (17.07) & $198(20.71)$ & \\
\hline \multirow[t]{2}{*}{ rs8105790 } & $\mathrm{TT}$ & $30(73.17)$ & 675 (70.61) & 0.724 \\
\hline & $\mathrm{TC} / \mathrm{CC}$ & $11(26.83)$ & 281 (29.39) & \\
\hline \multirow{2}{*}{ rs8109886 } & $\mathrm{CC}$ & 35 (85.36) & 773 (80.86) & 0.471 \\
\hline & $\mathrm{CA} / \mathrm{AA}$ & 6 (14.63) & $183(19.14)$ & \\
\hline \multirow[t]{2}{*}{ rs10853727 } & $\mathrm{TT}$ & $41(100)$ & 947 (99.06) & 0.533 \\
\hline & TC & $0(0.00)$ & $9(0.94)$ & \\
\hline
\end{tabular}

come from studies of populations with chronic HBV infection. There are few data on the prevalence of HBV infection in HCV patients in China where HCV infection is prevalent. Previous studies have shown that $2-10 \%$ of patients with HCV might also be infected with HBV in some regions. However, such a conclusion might not be applicable to other countries such as China because the geographic distribution of these two viruses is different and the previous studies were based on either a single centre or preselected patients from several centres. ${ }^{9} 11$ In this study, $4.11 \%$ of 997 patients with HCV were also infected with HBV. In our study, all patients with HCV were enrolled during a defined period of time at 28 representative large hospitals in provinces across China. ${ }^{12}$ This nationwide, multicentre, large-scale study should well reflect the current prevalence of $\mathrm{HBV} / \mathrm{HCV}$ dual infection among patients with HCV in China. A recent study by Zhang et $a l^{15}$ found that the anti-HCV-positive rate was $3.0 \%$ in 227808 study participants in Northeastern China. Therefore, there are an estimated 30 million individuals with chronic HCV infection in China, and millions of these might also become infected with HBV.

Population-based studies have shown that the prevalence of HBV increases with age. The prevalence in the elderly has been found to be higher than $6 \% .{ }^{15}$ The prevalence of $\mathrm{HBV} / \mathrm{HCV}$ dual infection also increases with age. A multivariate analysis demonstrated that $\mathrm{HBV} / \mathrm{HCV}$ dual infection was independently associated with age. Gender, residence in the south of China, a history of blood transfusion and host IL28B genotype were not associated with the presence of HBsAg.

The main pathway of virus transmission was found to be blood transfusion for both dual infection and HCV monoinfection in this study. Blood transfusion was the leading cause of HCV spread in China because routine HCV screening of blood donors was not introduced until the early nineties. ${ }^{16}$ Previous studies have shown that HCV genotype distribution is also associated with the pathway of virus transmission, with subtypes 1a, 3a and 4 being mostly related to intravenous drug use, while genotypes $1 \mathrm{~b}$ and 2 are associated with blood transfusion and other unsafe medical procedures. ${ }^{17} 18$ Our research showed that the main pathway of virus transmission in patients with genotype 1 or 2 was blood transfusion, while drug injection and other infections were mainly responsible for the spread of genotypes 3 and 6 .

Previous studies have shown that HBV and HCV might interact. It has been reported that HCV RNA levels were the same in both patients with $\mathrm{HBV} / \mathrm{HCV}$ dual infection and those with HCV infection alone. On the other hand, Zarski et $a l^{10}$ reported that the HCV RNA level was significantly lower in $\mathrm{HBV} / \mathrm{HCV}$ patients with 

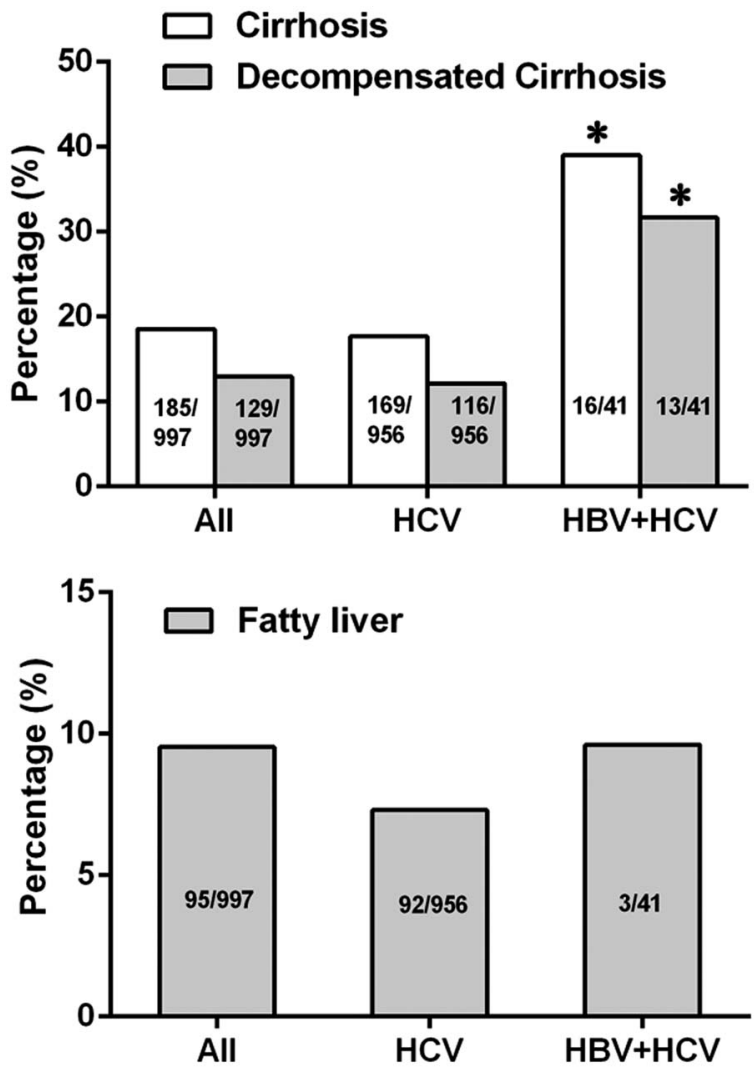

Figure 2 Cirrhosis and fatty liver in hepatitis B virus/hepatitis $\mathrm{C}$ virus $(\mathrm{HBV} / \mathrm{HCV})$ dual-infected patients and $\mathrm{HCV}$ monoinfected patients. (A) Prevalence of cirrhosis in patients with dual $\mathrm{HBV} / \mathrm{HCV}$ infection or HCV monoinfection. Numbers in the columns are the number of cirrhosis cases; ${ }^{*} \mathrm{p}=0.001$. (B) Prevalence of fatty liver in patients with dual $\mathrm{HBV} / \mathrm{HCV}$ infection or HCV monoinfection. Numbers in the columns are the number of fatty liver cases; $p=0.621$.

positive HBV DNA than in HBV/HCV patients with negative HBV DNA. In this study, we found similar HCV RNA levels in patients with HBV/HCV and HCV-monoinfected patients. Owing to the lack of HBV DNA data, we did not perform statistical analysis on stratified groups based on HBV DNA. The observed disparities may be accounted for by the huge statistical difference between the stratified groups based on HBV DNA data.

A systematic review of HCV genotypes in China showed that the main ones are $1 \mathrm{~b}$ and $2 \mathrm{a}$ subtypes. ${ }^{19} 20$ In this study, we found that the prevailing HCV genotype was still $1 \mathrm{~b}$ in both $\mathrm{HBV} / \mathrm{HCV}$ patients and HCV patients, followed by genotypes 2, 3 and 6 , in agreement with previous reports. ${ }^{21}$

The prevalence of IL28B rs12979860 CC genotypes was similar in both $\mathrm{HBV} / \mathrm{HCV}$ dual-infected patients and HCV monoinfected patients $(85.36 \%$ vs $83.99 \%$, $\mathrm{p}=0.814$ ). In China, the high frequency of the IL28B C allele (rs12979860) in both dual-infected patients and HCV monoinfected patients may contribute to the high rate of sustained virological response (SVR) to peginterferon plus ribavirin treatment. ${ }^{22-24}$ Direct-acting antivirals (DAAs) are gradually becoming the major therapy.
Overall SVR rates of DAAs were above $90 \%$ in numerous patient cohorts. Overall SVRs of ledipasvir and sofosbuvir were above $90 \%$ for untreated patients with HCV genotype 1 infection, most with a non-CC IL-28B genotype. ${ }^{25}$ Other studies have shown that patients with genotypes 4 and 5 who did not achieve SVR12 to ledipasvir and sofosbuvir treatments had non-CC IL-28B genotype. $^{26}{ }^{27} \mathrm{~A}$ randomised head-to-head study is needed to explore the effect of IL-28B on DAA treatment. This study laid the foundation for future research in this field.

It has been suggested that $\mathrm{HBV} / \mathrm{HCV}$ dual infection has a more severe evolution in the long term than HBV or HCV monoinfection. ${ }^{10}{ }^{28}$ In addition, several crosssectional studies found that dual infection is associated with a higher risk of liver cirrhosis and hepatic decompensation compared with HBV or HCV monoinfection, ${ }^{6}{ }^{29}$ without a broadly represented population. It should be emphasised that $\mathrm{HBV} / \mathrm{HCV}$ dual-infected patients are an extremely heterogeneous population. Most clinical studies performed so far did not examine extensively viral and host properties. In this study, the epidemiological, biological and virological characteristics and the host IL28B genotypes of dual-infected patients were mostly in line with those of HCV monoinfected patients. Our research also confirmed that $\mathrm{HBV} / \mathrm{HCV}$ dual infection was significantly associated with a higher risk of liver cirrhosis and hepatic decompensation than HCV monoinfection $(39.02 \%$ vs $17.69 \%$, $\mathrm{p}=0.001$; $31.70 \%$ vs $12.13 \%, \mathrm{p}=0.001$ ). Therefore, HBV/HCV dual infection might be the predominant cause of cirrhosis. Since cirrhosis is more severe in patients with HBV/ HCV dual infection, frequent monitoring of cirrhosis would lead to an earlier diagnosis, better management and prevention of hepatocellular carcinoma. However, owing to the poor economic conditions and low social status of most patients with $\mathrm{HBV} / \mathrm{HCV}$, the diagnosis of hepatitis and cirrhosis was always delayed, leading to delay in treatment. Therefore, patients with $\mathrm{HBV} / \mathrm{HCV}$ dual infection need more attention from medical professionals to ensure timely and effective treatment.

There are several limitations of this study. First, HBV viral load was not measured because of the shortage of serum in the dual infection group. Viral interactions between HBV and HCV need to be further explored. No data on occult HBV were available because HBV DNA analysis was not performed. This may have led to underestimation of the real burden of HBV in this study population. ${ }^{30}$ Second, no sequencing of $\mathrm{HBV}$ genes was carried out, which could have provided insights into molecular epidemiology, escape mutations and drug-resistance variants in this study population. No quantitative measurement of HBsAg was performed, which could have provided insights into the covalently closed circular DNA metabolic effect at the liver level. ${ }^{31}$ Third, a prospective study with an adequate follow-up period is needed to investigate the role of HBV infection in the outcome of HCV infection. Last, information 
about transmission was obtained by interview, thus recall bias is inevitable. Further study is needed to access the treatment response of $\mathrm{HBV} / \mathrm{HCV}$ dual-infected patients to either peginterferon/ribavirin or other direct-acting antiviral agents.

In conclusion, this nationwide, multicentre, large-scale population-based study indicates that the prevalence of $\mathrm{HBV} / \mathrm{HCV}$ dual infection in patients with $\mathrm{HCV}$ is $4.11 \%$. The HBV burden was moderate among HCV-infected patients in China. Liver cirrhosis was more common in patients with $\mathrm{HBV} / \mathrm{HCV}$ dual infection than in patients with HCV monoinfection, suggesting a need for closer monitoring of dual-infected individuals.

\section{Author affiliations \\ ${ }^{1}$ Center of Infectious Diseases, West China Hospital, Sichuan University, Chengdu, People's Republic of China \\ ${ }^{2}$ Division of Infectious Diseases, State Key Laboratory of Biotherapy, Sichuan University, Chengdu, People's Republic of China \\ ${ }^{3}$ Beijing Key Laboratory for Hepatitis $\mathrm{C}$ and Immunotherapy for Liver Disease, Peking University People's Hospital, Peking University Hepatology Institute, Beijing, People's Republic of China}

Acknowledgements We appreciate Professor Jia Shang in Henan Provincial People's Hospital, Professor Hong Chen in First Hospital of Lanzhou University, Professor Jun Li in First Affiliated Hospital with Nanjing Medical University, Professor Qing Xie in Shanghai Ruijin Hospital, Professor Zhiliang Gao in Third Affiliated Hospital of Sun Yat-sen University, Professor Lei Wang in Second Hospital of Shangdong University, Professor Jia Wei in First Affiliated Hospital of Kunming Medical College, Professor Jianning Jiang in First Affiliated Hospital of Guangxi Medical University, Professor Yongtao Sun in Fourth Military Medical University, Tangdu Hospital, Professor Zuojiong Gong in People's Hospital of Hubei Wuhan University, Professor Lunli Zhang in First Affiliated Hospital of Nanchang University, Professor Longfeng Zhao in First Affiliated Hospital of Shanxi Medical University, Professor Xiaoguang Dou in Shengjing Hospital of China Medical University, Professor Junqi Niu in First Hospital of Jilin University, Professor Hong You in Beijing Friendship Hospital, Capital Medical University, Professor Zhi Chen in First Affiliated Hospital of Medical College Zhe Jiang University, Professor Qin Ning in Affiliated Tongji Hospital of Tongji Medical College of Huazhong University of Science andTechnology, Professor Guozhong Gong in Second Xiangya Hospital of Central South University, Professor Shuhuan Wu in First Affiliated Hospital of Zhengzhou University, Professor Wei Ji in Ningxia People's Hospital, Professor Qing Mao in Southwest Hospital, Professor Shuchen Li in Second Affiliated Hospital of Harbin, Professor Shaofeng Wei in First Affiliated Hospital of Anhui Medical University, Professor Jian Sun in Nanfang Hospital, Southern Medical University, Professor Jiaji Jiang in First Affiliated Hospital of Fujian Medical University, Professor Lungen Lu in Shanghai First People's Hospital, Shanghai Jiao Tong University School of Medicine, Professor Hui Zhuang in Peking University Health Science Center for their contribution to this work.

Contributors LW and HT conceived the study, provided funding and revised the manuscript critically for important intellectual content. L-BY, H-YR and Y-JM made substantial contributions to data collection. E-QC, LB and L-YD conducted data analysis. L-BY and R-F Y participated in interpretation of data and manuscript preparation. L-BY drafted the manuscript and revised it according to all the authors' opinions. All authors have read and approved the final manuscript.

Funding This work was supported by grants from the China National Science and Technology Major Project for Infectious Diseases Control during the 12th Five-Year Plan Period (grant number2012ZX10002007-001-003, $2012 Z X 10002003$ and 2012ZX10002005) and from Bristol-Myers Squibb.

Competing interests None declared.
Ethics approval This study was approved by the ethics committee of 28 university-affiliated hospitals.

Provenance and peer review Not commissioned; externally peer reviewed.

Data sharing statement No additional data are available.

Open Access This is an Open Access article distributed in accordance with the Creative Commons Attribution Non Commercial (CC BY-NC 4.0) license, which permits others to distribute, remix, adapt, build upon this work noncommercially, and license their derivative works on different terms, provided the original work is properly cited and the use is non-commercial. See: http:// creativecommons.org/licenses/by-nc/4.0/

\section{REFERENCES}

1. Sievert W, Altraif I, Razavi HA, et al. A systematic review of hepatitis C virus epidemiology in Asia, Australia and Egypt. Liver Int 2011;31 (Suppl 2):61-80.

2. Saravanan S, Velu V, Nandakumar S, et al. Hepatitis B virus and hepatitis $C$ virus dual infection among patients with chronic liver disease. J Microbiol Immunol Infect 2009;42:122-8.

3. Lok AS, McMahon BJ. Chronic hepatitis B: update 2009. Hepatology 2009;50:661-2.

4. European Association for Study of Liver. EASL clinical practice guidelines: management of hepatitis $\mathrm{C}$ virus infection. $J$ Hepatol 2014;60:392-420

5. Shepard CW, Finelli L, Alter MJ. Global epidemiology of hepatitis C virus infection. Lancet Infect Dis 2005;5:558-67.

6. Caccamo G, Saffioti F, Raimondo G. Hepatitis B virus and hepatitis C virus dual infection. World J Gastroenterol 2014;20:14559-67.

7. Tyson GL, Kramer JR, Duan Z, et al. Prevalence and predictors of hepatitis B virus coinfection in a United States cohort of hepatitis C virus-infected patients. Hepatology 2013;58:538-45.

8. Bini EJ, Perumalswami PV. Hepatitis B virus infection among American patients with chronic hepatitis $C$ virus infection: prevalence, racial/ethnic differences, and viral interactions. Hepatology 2010;51:759-66.

9. Chu CJ, Lee SD. Hepatitis B virus/hepatitis C virus coinfection: epidemiology, clinical features, viral interactions and treatment. J Gastroenterol Hepatol 2008;23:512-20.

10. Zarski JP, Bohn B, Bastie A, et al. Characteristics of patients with dual infection by hepatitis B and $C$ viruses. $J$ Hepatol 1998;28:27-33.

11. Liu CJ, Chen PJ, Chen DS. Dual chronic hepatitis B virus and hepatitis C virus infection. Hepatol Int 2009;3:517-25.

12. Rao H, Wei L, Lopez-Talavera JC, et al. Distribution and clinical correlates of viral and host genotypes in Chinese patients with chronic hepatitis $\mathrm{C}$ virus infection. J Gastroenterol Hepatol 2014;29:545-53.

13. Chen X, Xuan M, Wu D. [Study of superinfection of HBV and HCV]. Zhonghua Liu Xing Bing Xue Za Zhi 1999;20:141-3.

14. Li W, Zhu Y, Hua Z. [Exploration on the association between the pattern of HBV markers and infection of HCV among population] Zhonghua Liu Xing Bing Xue Za Zhi 1994;15:212-14.

15. Zhang Q, Qi W, Wang X, et al. Epidemiology of hepatitis B and hepatitis $C$ infections and benefits of programs for hepatitis prevention in northeastern China: a cross-sectional study. Clin Infect Dis 2016;62:305-12.

16. Gower E, Estes C, Blach S, et al. Global epidemiology and genotype distribution of the hepatitis C virus infection. J Hepatol 2014;61:S45-57.

17. Esteban JI, Sauleda S, Quer J. The changing epidemiology of hepatitis C virus infection in Europe. J Hepatol 2008;48:148-62.

18. Pawlotsky JM, Tsakiris L, Roudot-Thoraval F, et al. Relationship between hepatitis $C$ virus genotypes and sources of infection in patients with chronic hepatitis C. J Infect Dis 1995;171:1607-10.

19. Cui Y, Jia J. Update on epidemiology of hepatitis B and C in China. $J$ Gastroenterol Hepatol 2013;28(Suppl 1):7-10.

20. Su YY, Liu HX, Wang N. [Hepatitis $C$ virus genotypes in China: a systematic review]. Zhonghua Liu Xing Bing Xue Za Zhi 2013;34:80-4.

21. Lu L, Nakano T, He Y, et al. Hepatitis C virus genotype distribution in China: predominance of closely related subtype $1 \mathrm{~b}$ isolates and existence of new genotype 6 variants. J Med Viro 2005; 75:538-49.

22. Dong ZX, Zhou HJ, Xiang XG, et al. IL28B genetic variations are associated with treatment response of patients with chronic hepatitis C in a Chinese Han population. J Dig Dis 2015;16:90-7.

23. Mi Y, Gao YT, Jiao XL, et al. The role of interleukin-28b gene polymorphisms in Chinese patients with chronic hepatitis $C$ treated with pegylated interferon and ribavirin. Hepat Mon 2014;14:e18793. 
24. Liao XW, Ling $\mathrm{Y}, \mathrm{Li} \mathrm{XH}$, et al. Association of genetic variation in IL28B with hepatitis $C$ treatment-induced viral clearance in the Chinese Han population. Antivir Ther 2011;16:141-7.

25. Afdhal N, Zeuzem S, Kwo P, et al. Ledipasvir and sofosbuvir for untreated HCV genotype 1 infection. N Engl J Med 2014;370:1889-98

26. Abergel A, Asselah T, Metivier S, et al. Ledipasvir-sofosbuvir in patients with hepatitis $C$ virus genotype 5 infection: an open-label, multicentre, single-arm, phase 2 study. Lancet Infect Dis 2016;16:459-64.

27. Abergel A, Metivier S, Samuel D, et al. Ledipasvir plus sofosbuvir for 12 weeks in patients with hepatitis $C$ genotype 4 infection. Hepatology 2016;64:1049-56.
28. Sagnelli E, Pasquale G, Coppola N, et al. Influence of chronic coinfection with hepatitis B and C virus on liver histology. Infection 2004;32:144-8.

29. Villari D, Pernice M, Spinella S, et al. Chronic hepatitis in patients with active hepatitis $B$ virus and hepatitis $C$ virus combined infections: a histological study. Am J Gastroenterol 1995;90:955-8.

30. Coppola N, Onorato L, Pisaturo M, et al. Role of occult hepatitis B virus infection in chronic hepatitis C. World J Gastroenterol 2015;21:11931-40.

31. Xie $Q$, Jiang $X$, Zhang $Y$, et al. Intrahepatic hepatitis $B$ virus covalently closed circular DNA correlation with serum HBV DNA, serum HBsAg, alanine aminotransferase and age. Zhonghua Gan Zang Bing Za Zhi 2015;23:418-21. 